\title{
Preface to the Special Issue
}

\author{
Sindu George ${ }^{1} \cdot$ Paul Swan $^{1}$
}

Published online: 11 April 2020

() The Australian Association for Research in Education, Inc. 2020

Supported by the Australian Association for Research in Education (AARE), editors of this Special Issue together with expert volunteers launched a series of workshops in 2018 to address gaps in quantitative methods offerings in educational research in Australia. In September 2017, we (Drs. Sindu George and Paul Swan, Monash University) under the mentorship of established researchers (Professors Helen Watt at The University of Sydney, Paul Richardson at Monash University, and Philip Parker at the Institute for Positive Psychology and Education (IPPE) at the Australian Catholic University) successfully secured an AARE Strategic Initiatives Grant to organise the 2018 'Quantitative Summit'. These grants are awarded for capacity building of educational researchers to conduct high-quality research, providing forums for knowledge sharing and critical engagement, and promoting visibility and uptake of research by educational policy and practice.

\section{The 2018 'Quantitative Summit'}

In 2011, the Associate Research Deans of Education Network (ARDEN) produced a report documenting Australian education academics' and research students' needs that AARE may be able to help meet. Some 360 researchers (including established and early career researchers, as well as students) expressed strong interest in opportunities to attend AARE-sponsored research methods workshops, highlighting a "terrible shortage of quantitative expertise in Australia" (Watt 2011, p. 8) and reported a particular interest in learning about survey methods. Our 2018 Quantitative Summit thus sought to address this identified gap concerning quantitative methods through sequenced planned workshops focused on survey design and analyses, offering introductory to complex topics contributed by local and international experts, rarely available in Australia. A highly subsidised price was made possible

\footnotetext{
1 Watt, H. M. G. (2011). ARDEN research methodology survey Dec'10-Feb'11: Unpublished Summary Report to AARE Executive.

Sindu George

sindu.george@monash.edu

1 Monash University, Wellington Rd, Clayton, VIC 3800, Australia
} 


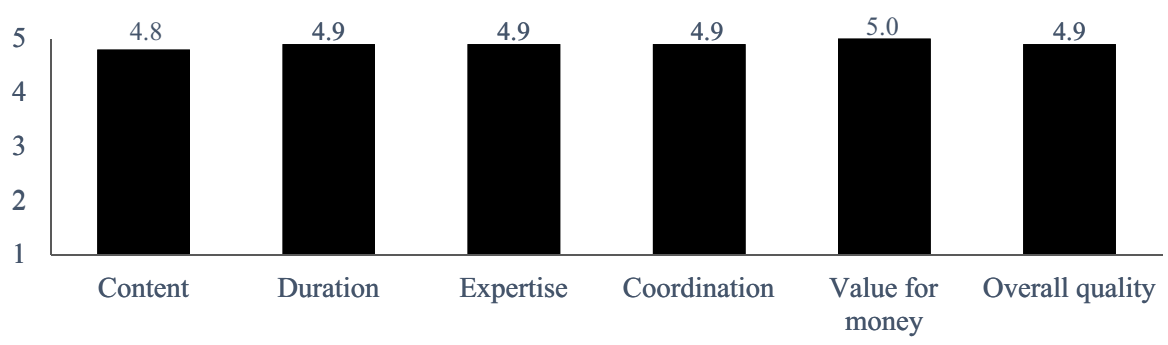

Fig. 1 Participants' feedback on the 2018 AARE Quantitative Summit

by presenters volunteering their time and expertise. The 2018 Quantitative Summit consisted of a series of ten sessions over five days: the first three days at Monash University (11 to 13 July) and the remaining two at The University of Sydney (30 November to 1 December). Our overarching aims were to

- promote critical and engaged dialogue in the underserved area of quantitative methods in Australian educational research;

- explore quantitative survey design and analyses;

- interact with other researchers for like-minded intellectual exchange; and

- build towards a focused education research community in Australia of developing quantitative expertise.

\section{Summit Participants and Outcomes}

The 2018 Quantitative Summit was launched at the 2017 AARE annual conference in Canberra. We were inundated with participants wishing to attend-both workshop series were quickly over-subscribed with the maximum 58 participants we could accommodate. Participants included research students $(35 \%)$, early career (53\%) and mid-career researchers (12\%) from organisations such as the Australian Council for Educational Research (ACER), University of Queensland, University of New South Wales, University of Sydney, Western Sydney University, Royal Melbourne Institute of Technology (RMIT), Deakin and Monash Universities. Workshops were highly appreciated by participants, whose feedback on anonymous evaluation forms $(N=45$, response rate $77.6 \%)$ indicated satisfaction with the content covered, duration, presenters' expertise, coordination, value for money, and overall quality. Mean scores are presented in Fig. 1, substantiated by unsolicited qualitative feedback, for example:

Thank you for organising the 2018 Quantitative Summit. I was fortunate enough to attend Part 1 at Monash University, and found it to be an incredibly enriching and inspiring experience. I also want to express my sincere appreciation and gratitude to the academic staff who gave up their time to run this workshop for free. It is almost unheard of, and their willingness to so generously contribute their time and knowledge is a testament to their professional- 
ism and commitment to the discipline. As a PhD student, it is so motivating to be around such wonderful academics, and certainly gives me something to aspire to!

(Attendee, 2018 Quantitative Summit).

A key deliverable we had promised in our successful grant application was the opportunity for participants to present their research in a resultant Special Issue of the Australian Educational Researcher (AER) featuring methods covered in the 2018 Quantitative Summit. We are pleased to offer the present Special Issue, 'Person- and Variable-Centred Quantitative Analyses in Educational Research: Insights concerning Australian students' and teachers' engagement and wellbeing', including selected papers from participants and presenters of the 2018 Quantitative Summit, with a synthesising discussion article.

\section{Selection of Manuscripts for the Special Issue}

Participants were initially invited at the workshops to submit a 500-word expression of interest (EOI), eleven of which were independently reviewed by the five members of the Organising Committee. EOIs were scored $(1=$ not acceptable to $5=$ superior $)$ against criteria of focus and relevance, context and contribution, design and methods, results and significance, and clarity and composition. Each reviewer also provided an overall recommendation whether to invite or reject the development of a full manuscript submission along with qualitative feedback comments. Selected full paper submissions were consequently invited for six EOIs. Following the journal's usual process, each manuscript was independently double-blind peer reviewed by two reviewers, providing for up to three rounds of revisions and avoiding any potential or perceived conflicts of interest. The four final articles accepted and included in the Special Issue are as follows:

- 'Starting and staying strong: pre-service primary teachers' attitudinal profiles towards science learning and their outcomes in an introductory science unit" by Deborah Pino-Pasternak and Simone Volet;

- "Positive attitudes towards mathematics and science are mutually beneficial for student achievement: a latent profile analysis of TIMSS 2015" by Nathan Berger, Erin Mackenzie, and Kathryn Holmes;

- "Social climate and avoidance of help-seeking in secondary mathematics classes" by Roy Smalley and Sarah Hopkins;

- "Teacher burnout and turnover intent" by Natalia Rajendran, Helen Watt, and Paul Richardson.

A synthesising discussion by Helen Watt and Philip Parker "Person- and variablecentred quantitative analyses in educational research: insights concerning Australian students' and teachers' engagement and wellbeing", distils both methodological and substantive contributions to draw out the importance and implications of quantitative methods in contemporary Australian educational research. 


\section{Outline of the Summit Sessions}

- Workshop Series 1 at Monash was strategically timed to precede the biennial International Society for the Study of Behavioural Development Conference (ISSBD) to access international visitors. Day 1 workshops were run by Monash faculty: Ms. Natalia Rajendran (Measuring relationships between factors: An introduction to correlational and multiple regression analyses), Dr. Shane Costello (Scale validation using exploratory factor analysis), Dr. Zoe Morris (Exploring individual differences through cluster analysis) and Professor Paul Richardson (Who are in the clusters? An illustration of teachers' engagement and coping profiles from a large-scale longitudinal study).

- Ms. Rajendran's workshop introduced the correlation coefficient and when to use each form of correlation (Chi-square, Spearman, and Pearson), interpreted what a correlation means in practice, and looked at examples of correlations in research problems. Building on correlation analysis, multiple regression analysis estimates the dependence between one or more independent variables ('predictors') and a dependent variable ('outcome'). Hands-on activities were conducted using SPSS software to illustrate and consolidate concepts learned.

- Dr. Costello's workshop outlined how the quantitative researcher's "skills toolkit" can be enhanced with an understanding of the conceptual and practical aspects of developing a scale to measure a construct of interest. His workshop introduced the classical test theory, factor analysis, and provided applied examples.

- Dr. Morris explained how cluster analysis can explore individual differences for subgroups on variables of interest. Cluster analysis is a form of personcentred analysis (as opposed to variable-centred methods such as regression) used as an exploratory technique to identify homogenous subgroups.

- Professor Richardson then presented illustrations of cluster analysis from his research, drawing on beginning teachers' engagement and coping profiles from the FIT-Choice project (www.fitchoice.org). The potential of linking cluster with qualitative thematic analyses was illustrated as a useful heuristic.

Ms. Natalia Rajendran is completing her PhD at Monash University on teacher stress and burnout, and her research is included in this Special Issue as the fourth empirical article. She has taught applied statistics at Swinburne University, and quantitative research methods at Monash University. Dr. Shane Costello's expertise lies in the study of individual differences (personality and cognitive abilities) to understand who people are, how they differ, and why they do what they do. He is particularly interested in psychometrics (or measurement science) concerning the design, construction, validation and evaluation of psychological instruments. Dr. Zoe Morris is an educational and developmental psychologist who lectures in the Counselling and Psychology programs at Monash University, including in applied statistics and psychological assessment. Professor Paul Richardson at the time of the Summit was Associate Dean Research in the Faculty of Education at Monash University, and he is engaged in a longitudinal study of the career choice 
motivations of teachers, their self-efficacies, and career trajectories for different types of beginning and mid-career teachers.

On Day 2 a full-day workshop was delivered by Professor Helen Watt from The University of Sydney (An introduction to structural equation modelling). This labbased workshop extended on sessions 1 and 2 of the preceding day to provide the theoretical foundation to measurement, structural, and fully latent variable models, with practical applications using the AMOS software. Professor Watt is an ARC Future Fellow and Professor of Educational Psychology at The University of Sydney, who previously taught Fundamentals of SEM at ACSPRI (www.acspri.org.au). Her interests include gender and motivation, educational and occupational choices among youth (www.stepsstudy.org) and teachers (www.fitchoice.org), and quantitative analyses for developmental data.

Day 3 opened with four participant roundtable sessions relating quantitative methods to participants' current or future research proposals, where targeted feedback was obtained from matched presenters in a constructive group format. This was followed by a workshop offered by Professor Anne Frenzel (Multilevel modelling with MPlus), Professor at the Department of Psychology at Ludwig Maximilians University in Munich, Germany, skilled in methodologies for analyses of complex longitudinal data involving multilevel modelling and contextual effects. Her labbased session introduced the theoretical foundation to multilevel modelling for "nested data structures" (individuals nested in groups, or multiple measures nested in individuals), including practical applications using SPSS and MPlus. Professor Frenzel's research is focused on the emotional experiences of students and teachers and how they shape classroom functioning.

Workshop Series 2 in Sydney preceded the 2018 AARE annual conference to maximise opportunity and convenience for participants to attend. Day 1 was led by researchers from the Institute for Positive Psychology and Education (IPPE) at the Australian Catholic University: Professor Philip Parker (How to analyse PISA data), followed by Ms. Emma Divine, Dr. Geetanjali Basarkod, and Dr. Emma Bradshaw (Scale abbreviation using genetic algorithms), demonstrating the GAabbreviate package in $R$ developed by Dr. Baljinder Sahdra, Professor Joseph Ciarrochi, Professor Philip Parker, and Assoc. Professor Luca Scrucca.

Professor Parker outlined the large amount of research in education, psychology, sociology, and economics that draws on data from the Programme for International Student Assessment (PISA). Despite the availability of these data, there is relatively little training on how to use these complex datasets. Participants were provided with training in how to analyse the PISA 2003 database in R and Rstudio including the use of replicate weights and plausible values for achievement. This foundation is useful also for other PISA cycles and databases that use complex survey design (e.g. TIMSS, ESS, LSAY, LSAC, and TREE). The session covered the use of weights, when to use multilevel models and when not, and how to use plausible values. Professor Parker is the Deputy Director at IPPE, whose major research interests concern educational inequality, developmental transitions, and educational attainment.

The following workshop by Ms. Emma Devine, Ms. Geetanjali Basarkod, and Dr. Emma Bradshaw focused on genetic algorithms as robust machine learning approaches for abbreviating a large set of variables into a shorter subset while 
capturing the maximum variance in the data. Genetic Algorithms can be used to abbreviate long questionnaires, making them more suitable for use in longitudinal and intervention studies, as well as clinical practice where measurement time is often limited. Multidimensional scales can also be abbreviated using the genetic algorithm method. Using three examples of real datasets for published and ongoing projects, their workshop demonstrated how the method can be easily implemented using the GAabbreviate package in R. Illustrations included abbreviating a 12-item unidimensional measure of body image psychological flexibility to a 5-item short form that explained $96 \%$ of the variance in the original; abbreviating the Multidimensional Experiential Avoidance Questionnaire from 62 to 30 items; and the Aspiration Index from 35 to 7 items - all while maintaining statistical performance and construct validity.

Ms. Emma Devine is a PhD Candidate at IPPE whose research uses social network analysis to investigate the impact of friendship groups on individuals' wellbeing. Previously she completed an undergraduate degree in Psychology and a Masters in Psychological Science at University College Dublin. Dr. Geetanjali Basarkod is a postdoctoral research fellow at IPPE whose $\mathrm{PhD}$ research aimed to validate a new measure to assess the frequency and motivation for six behaviours hypothesised to promote well-being. She completed a Bachelor of Science in Psychology (Honours) at the University of Warwick, England. Dr. Emma Bradshaw is a postdoctoral research fellow at IPPE; after completing her Bachelor of Psychological Science (Honours) in 2014, she turned her focus to examining life-goals and aspirations, to explore how patterns of intrinsic and extrinsic aspirations (derived using latent profile analysis) can be used to predict various indices of optimal functioning.

Day 2 Workshops were presented by Dr. Nathan Berger from Western Sydney University (Introduction to latent class analysis using $R$ ), and Professor Jim Tognolini from The University of Sydney (Introduction to Rasch theory for building measurement scales using RUMM). Dr. Berger offered a lab-based session including theory and applications concerning latent class analysis and latent profile analysis, which are more sophisticated versions of cluster analysis (building on preceding sessions) to identify unobserved (latent) subgroups within a dataset based on shared attitudinal or behavioural characteristics. This is an important tool in the quantitative educational researcher's toolkit, illustrated utilising MS Excel, SPSS, R and RStudio. Dr. Nathan Berger is a Postdoctoral Research Fellow in science, technology, engineering and mathematics (STEM) education at Western Sydney University. He has degrees in information technology, secondary social sciences, and quantitative educational research. His $\mathrm{PhD}$ was recently awarded in the social psychology of education by the University of Newcastle.

Professor Tognolini delivered a workshop on how to build a measurement scale using the Rasch family of models, to produce meaningful measures. Practical illustrations were included using the Rasch Unidimensional Models for Measurement (RUMM) program, with opportunity for participants to use RUMM and interpret the output. Professor Jim Tognolini is Director of the Measurement and Assessment Hub at The University of Sydney, with a distinguished career in system-wide assessment and as senior advisor on measurement issues for every State and Territory Education Department and Examination Board in Australia and New Zealand. 
His specialist research and educational evaluation work focuses primarily on educational assessment and the application and appropriateness of measurement models and theoretical perspectives to education and learning in both local and international contexts.

\section{About the Guest Editors}

Sindu George, PhD, is an early career researcher and Lecturer at Monash University, who has hands-on experience in statistical analysis of data in social science research including scale validation, univariate and multivariate analyses, and structural equation modelling. She is a member of the editorial board of the Australian Journal of Education and formerly served as an Associate Editor for The International Journal of Pedagogy and Curriculum (2013), and International Journal of Behavioral Sciences (2011). She has reviewed for journals including AERA Open, Teaching and Teacher Education, Review of Educational Research, and the Australian Educational Researcher; she also reviews conference proposals for the Australian Association for Research in Education (AARE), the European Association for Research on Learning and Instruction (EARLI), and International Society for the Study of Behavioural Development (ISSBD).

Helen Watt, PhD, is Professor of Educational Psychology at The University of Sydney and ARC Future Fellow 2017-2021 with over 23 years' teaching experience in quantitative methods at four universities and previously at ACSPRI. She is Associate Editor for AERA Open and on editorial boards of International Journal of Quantitative Research in Education, Contemporary Educational Psychology and the Australian Journal of Education. She was previously Associate Editor for Educational Research Review and on editorial boards for the Journal of Experimental Education; Journal for Research on Adolescence; Equal Opportunities International; and Equity, Diversity and Inclusion. Helen has edited journal special issues for Educational Research and Evaluation (2006), Learning \& Instruction (2008), Asia-Pacific Journal of Teacher Education (2012), International Journal of Gender, Science and Technology (2013); and books including Gender and occupational outcomes (APA 2008), Teacher motivation (Routledge 2014), Global perspectives on teacher motivation (CUP 2017), and is founder of Network Gender \& STEM.

Paul Swan, PhD, is an early career researcher and Lecturer at Monash University. He has presented papers at conferences of the Australian Association for Research in Education (AARE), European Association for Research on Learning and Instruction (EARLI), American Educational Research Association (AERA), and International Society for tfighe Study of Behavioural Development (ISSBD). He has reviewed conference papers for AARE and EARLI, and journal articles for the Australian Educational Researcher.

Philip Parker, PhD, is a Professor at the Institute for Positive Psychology and Education (IPPE) at the Australian Catholic University. His research uses large-scale and longitudinal databases from countries including Australia, the U.S., U.K., Germany, and Finland where he focuses on career pathways, educational attainment, and individual differences related to youths' transition from school to work or further 
education. Phil has served on the editorial board of the Journal of Educational Psychology and currently serves on the editorial board of Learning and Instruction. He reviews for Developmental Psychology, Child Development, Research in Social Stratification and Mobility, Journal of Personality, Higher Education, British Journal of Educational Psychology, Children and Society, Journal of Economic Inequality, and many other journals.

We would like to take this opportunity to thank all workshop presenters for their voluntary contribution of time and effort, without whom this event would not have been realised. We thank all workshop attendees whose enthusiasm made the 2018 Quantitative Summit a huge success. We also thank the authors who contributed to this Special Issue and the reviewers for their time and expert advice to ensure the best quality output. As early career researchers, we have learnt much from this process and we express our sincere thanks to our mentors for their valuable advice; AARE for funding and supporting the summit; and the AER Editorial team, especially Assoc. Professor Nicole Mockler and Dr. Meghan Stacey for supporting us throughout the publishing process. We would particularly like to thank Professor Helen Watt for her guidance throughout each stage of organising the 2018 Quantitative Summit and publishing this special issue. We hope you enjoy reading these articles showcasing research applying a range of quantitative techniques.

Publisher's Note Springer Nature remains neutral with regard to jurisdictional claims in published maps and institutional affiliations.

Sindu George is an early career researcher and Lecturer at Monash University, who has hands-on experience in statistical analysis of data in social science research including scale validation, univariate and multivariate analyses, and structural equation modelling. She is a member of the editorial board of the Australian Journal of Education and formerly served as an Associate Editor for The International Journal of Pedagogy and Curriculum (2013), and International Journal of Behavioral Sciences (2011). She has reviewed for journals including AERA Open, Teaching and Teacher Education, Review of Educational Research, and the Australian Educational Researcher; she also reviews conference proposals for the Australian Association for Research in Education (AARE), the European Association for Research on Learning and Instruction (EARLI), and International Society for the Study of Behavioural Development (ISSBD).

Paul Swan is an early career researcher and Lecturer at Monash University. He has presented papers at conferences of the Australian Association for Research in Education (AARE), European Association for Research on Learning and Instruction (EARLI), American Educational Research Association (AERA), and International Society for the Study of Behavioural Development (ISSBD). He has reviewed conference papers for AARE and EARLI, and journal articles for the Australian Educational Researcher. 